CoV-2, referred to as COVID-19, is determined as a pandemic on 11 March 2020. To this day, no therapy has been deemed effective, all of which are still under research. The virus infected the respiratory epithelium of the lower airways. ${ }^{2}$ COVID-19 has diverse spectrums from asymptomatic infection to respiratory failure and patient death. ${ }^{3}$ Severe cases are related to cytokine storms that occurred as a result of excessive immune dysregulation, followed by thrombophilia and endothelial dysfunction., ${ }^{4,5}$

Cytokine storm is an unchecked feed ward activation and amplification of host range, which will trigger a massive release of a cytokine such as interferon- $\gamma$ (IFN- $\gamma$ ), TNF, interleukin (IL-1, and IL-6). ${ }^{4}$ To date, no therapy has been deemed effective, and extensive research is conducted, including in Indonesia. Therapeutic Plasma Exchange (TPE) is among the developed treatments included in supportive therapy, and administered to severe and critical patients. ${ }^{2}$ This therapy has been known for more than a century and was developed for immune disorders, and is relatively safe and effective. ${ }^{6}$ It has been reported, the patients had TPE as a mode of treatment. The TPE group was associated with higher extubation rates than the non-TPE cohort. Additionally, patients on TPE had a lower post plasma exchange mortality compared to patients not on TPE. ${ }^{2}$ Keith P et al reported, patient with TPE will rapid improvement and was weaned off from the ventilator. The respiratory status had improved and was able to alternate between noninvasive positive pressure ventilation (NIPPV) and highflow nasal cannula. ${ }^{7}$ Another report, a patient with TPE, biochemical and clinical improvement continued over the following days together with an increase in the oxygenation index. ${ }^{3}$

\section{CASE DESCRIPTION}

A forty-one years old man visited UNS Hospital with height $170 \mathrm{~cm}$, body weight 70 $\mathrm{kg}$ with body mass index 24.22 (normoweight) without any comorbidity reporting fever and shortness of breath on October first, 2020. He received treatment from a different hospital for nausea, high fever, and chest X-ray showing normal. Therefore, treatment for typhoid fever was administered for him. The patient was referred to UNS Hospital after having no improvement after four day hospitalization and started to experience shortness of breath.
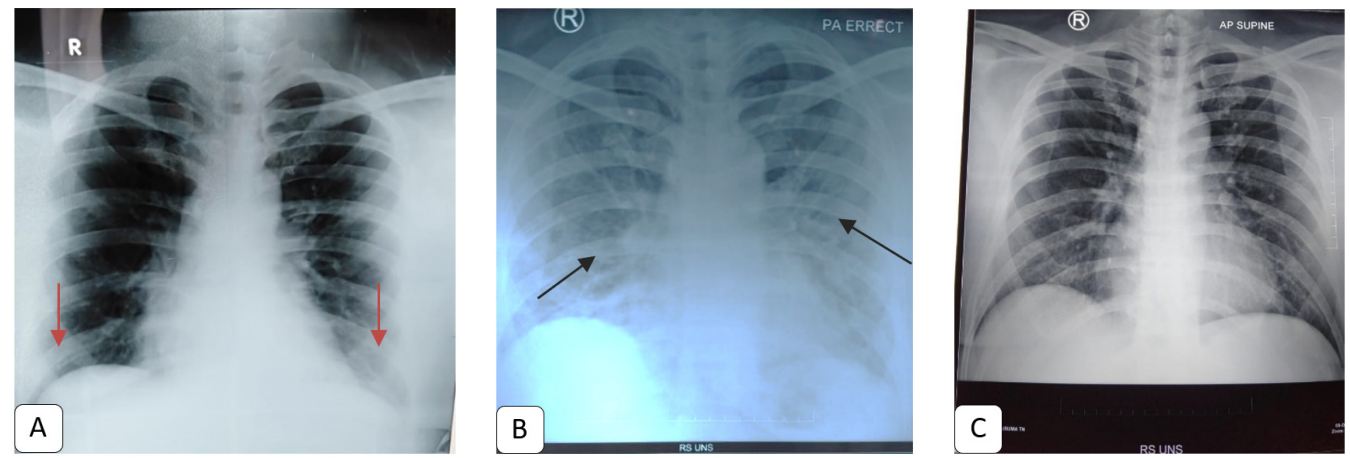

Figure 1. Radiological data of the stages of the illness. Figure A, September, 27th 2020, the patient experienced fever and nausea and diagnosed with typhoid fever, X-ray result minimal consolidation opacities bilateral in lower zone (red arrows). Figure B, October 1st 2020, the patient reported shortness of breath, and the blood gas analysis showed respiratory failure, a visible increase in broncho vascular streak and infiltrates bilateral (black arrows). Figure $\mathrm{C}$, October, 9th 2020, the patient received TPE twice, the chest X-ray result went back to normal.

At the initial examination, the routine blood check result showed a relatively normal condition with only a slight increase in neutrophil lymphocyte ratio (NLR=3.9). However, the number is still below the average COVID-19 result of $5 .^{8}$ The blood gas analysis showed an oxygen tension $\left(\mathrm{PaO}_{2}\right)$ of $95 \mathrm{mmHg}$ and $\mathrm{O}_{2}$ saturation $\left(\mathrm{SaO}_{2}\right)$ of $98 \%$ in the room air $\left(\mathrm{FiO}_{2}=\right.$ 
$21 \%$ ) or $\mathrm{FiO}_{2} / \mathrm{PaO}_{2}$ ratio $=457$, however the realtime polymerase chain reaction (RT PCR) for SARS CoV2 from nasopharyngeal swab showed a positive result. After the patient received a receiving standard therapy for COVID-19 following the Ministry of Health and Perhimpunan Dokter Paru Indonesia (PDPI)guideline with hydroxychloroquine $400 \mathrm{mg} /$ daily, azithromycin $500 \mathrm{mg} /$ daily, oseltamivir $75 \mathrm{mg} / 12$ hours, and vitamin C $1000 \mathrm{mg} / 8$ hours, he experienced worse shortness of breath. ${ }^{9}$ Thus, another blood gas analysis and chest X-ray were conducted for clinical evaluation (Figure 1A). This new blood gas test showed the decrease in $\mathrm{PaO}_{2}$ from 95 $\mathrm{mmHg}$ to $84 \mathrm{mmHg}$ on the administration of $\mathrm{O}_{2}$ 3 litre/minute $\left(\mathrm{FiO}_{2}=33 \%\right)$ resulted in a $\mathrm{PaO}_{2} /$ $\mathrm{FiO}_{2}$ ratio of 254.5; therefore, it falls under the mild ARDS category.

The result of the second chest X-ray showed an increase in infiltrates and broncho vascular marking (Figure 1B). Another examination performed was D-Dimer $=629.29 \mathrm{ng} / \mathrm{mL}$, which means that there was thrombophilia (normal level $<500 \mathrm{ng} / \mathrm{mL}$ ) and the result of hs-CRP $=18.51 \mathrm{mg} / \mathrm{L}$ (normal level $<0.3 \mathrm{mg} / \mathrm{L}$ ) which indicated the presence of viral infection.
In COVID-19 infection with ARDS, respiratory failure, and thrombophilia additional antiinflammatory therapy was administered using dexamethasone $2.5 \mathrm{mg} / 8$ hours, heparin $18 \mathrm{iu} /$ kg bodyweights/hour, and TPE was performed.

TPE was performed on October, $4^{\text {th }} 2020$ and October $8^{\text {th }} 2020$, because of the patient was diagnosed with mild ARDS and increase of IL-6 in the COVID-19 isolation room of UNS Hospital using the haemonetics machine MTS Plus and kit 980 E. According to the patient's weight (70 kg) and hematocrit of 34.8, a total of 3204 cc plasma fluid will be extracted. In stage I, $2000 \mathrm{cc}$ of plasma fluid was extracted, and another plasma fluid will be extracted in stage II after considering the patient's clinical condition. In stage II, 1200 cc of fluid was extracted and was replaced with 4 flashes ( $250 \mathrm{cc}$ each) of albumin $5 \%$, and thus, the replacement fluid consists of $1000 \mathrm{cc}$ albumin 5\% and $1000 \mathrm{cc}$ crystalloid liquid. Before TPE was administered, an examination was conducted, and similar IL-6 levels $(391.220 \mathrm{pg} / \mathrm{ml})$, and $\mathrm{P} / \mathrm{F}$ ratio (250) were obtained, which means there was no improvement compared to the previous examination. After the second TPE was administered in the interval of 5 days, significant

Table 1. Laboratory finding on October, $1^{\text {st }} 2020$.

\begin{tabular}{lcc}
\hline Examination & Result & Unit \\
\hline Haemoglobin & 11.8 & $\mathrm{~g} / \mathrm{dl}$ \\
Haematocryte & 34.6 & $\%$ \\
Leukocyte & 7.53 & $10^{3} / \mathrm{uL}$ \\
Platelets & 178 & $10^{3} / \mathrm{uL}$ \\
Erythrocytes & 4.16 & $10^{6} / \mathrm{uL}$ \\
Eosinophils & 0.3 & $\%$ \\
Basophils & 0.0 & $\%$ \\
Neutrophils & 73.5 & $\%$ \\
Lymphocytes & 19.8 & $\%$ \\
Monocytes & 6.4 & $\%$ \\
Ureum & 14.0 & $\mathrm{mg} / \mathrm{dL}$ \\
Creatinin & 0.91 & $\mathrm{mg} / \mathrm{dL}$ \\
Natrium & 135.33 & $\mathrm{mmol} / \mathrm{L}$ \\
Kalium & 3.46 & $\mathrm{mmol} / \mathrm{L}$ \\
Chloride & 97.87 & $\mathrm{mmol} / \mathrm{L}$ \\
\hline
\end{tabular}


clinical improvement was observed. There is no adverse effect of TPE on this patient such as hypotension and haemorrhage. The IL-6 measure decreased to $25.512 \mathrm{pg} / \mathrm{ml}$ (normal level 5-15 $\mathrm{pg} / \mathrm{ml}$ ), TNF- $\alpha=6.852 \mathrm{pg} / \mathrm{ml}$ (normal level 10$100 \mathrm{pg} / \mathrm{ml}$ ) $\mathrm{SaO}_{2}=99$ percent at the room air $(21 \%)$ and $\mathrm{P} / \mathrm{F}$ ratio $=428.5$ or normal (Table 1$)$.
The patient experienced clinical improvement supported by the chest X-ray results, which showed a decrease in ground glass opacity to normal condition (Figure 1C). The patient has given the consent for clinical data to be used as part of a study and published anonymously.

Table 2. Comparison of laboratory parameter and cytokine

\begin{tabular}{|c|c|c|c|}
\hline & $\begin{array}{c}\text { October, } 2^{\text {nd }} 2020 \\
\text { (Day -1) }\end{array}$ & $\begin{array}{c}\text { October, } 3^{\text {rd }} 2020 \\
\text { (Before TPE) }\end{array}$ & $\begin{array}{c}\text { October, } 9^{\text {th }} 2020 \\
\text { (After TPE) }\end{array}$ \\
\hline $\mathrm{pH}$ & 7.55 & 7.46 & - \\
\hline $\mathrm{BE}$ & 5 & 0.7 & - \\
\hline $\mathrm{pCO}_{2}$ & 31 & 34 & - \\
\hline $\mathrm{pO}_{2}$ & 95 & 84 & 90 \\
\hline Hematocrit & 34.6 & 34.8 & - \\
\hline $\mathrm{HCO}_{3}$ & 27.4 & 24.2 & - \\
\hline Total $\mathrm{CO}_{2}$ & 28.4 & 25.2 & - \\
\hline $\mathrm{O}_{2}$ saturation & $98 \%$ & $97 \%$ & $99 \%$ \\
\hline $\mathrm{FiO}_{2}$ & 21 & $33 \%$ & $21 \%$ \\
\hline IL 6 & - & 391.22 & 25.51 \\
\hline TNF $\alpha$ & - & 22.85 & 6.85 \\
\hline $\mathrm{P} / \mathrm{F}$ ratio & 457 & 254.5 & \\
\hline D-Dimer & 629.29 & - & 471 \\
\hline hs-CRP & 18.51 & - & - \\
\hline
\end{tabular}

\section{DISCUSSION}

The leading causes of death in patients with COVID-19 infection are ARDS and cytokine storm syndrome. ${ }^{2}$ This host response to infection has been well described and involves a complex interaction of cytokine storm, inflammation, endothelial dysfunction, and pathologic coagulation. ${ }^{7}$ Additionally, $50 \%$ of patients presenting with cytokine storm syndrome usually develop ARDS. In severe COVID-19 infection, TPE with followed albumin returning, removes toxins and deleterious inflammatory cytokines such as IL-1, IL-6, granulocyte-colony stimulating factor, tumor necrosis factor, and other inflammatory parameters. These inflammatory mediators can trigger a cytokine storm-mediated immune injury to the different target organs, resulting in capillary leak syndrome, progressive lung injury, respiratory failure and ARDS, shock, acute kidney injury, and liver impairment. Simultaneous replacement with normal plasma helps to improve hypercoagulable state, reduce cytokine response. ${ }^{2,10}$

The patient diagnosed with COVID-19, ARDS, respiratory failure, and thrombophilia experienced clinical improvement after TPE was administered. The therapy, also known as plasmapheresis, has been implemented for more than one century. ${ }^{11}$ In the guideline issued by the American Society of Apheresis for ARDS case, the administration of TPE is included in category III, or the optimum role of apheresis therapy is not established. Decision-making should be individualized. ${ }^{12}$

COVID-19 rarely caused severe respiratory failure, especially at the beginning of the 
infection. ${ }^{7}$ Usually, severe respiratory failure is caused by a highly pathogenic strain. Several studies in Wuhan showed that the increase of inflammation caused by cytokine storm is connected to mortality, with low $\mathrm{SaO}_{2}$ that will increase IL-6, IL-10, C-reactive protein (CRP), and TNF- $\alpha$, which in turn will cause cytokine storm. ${ }^{3}$ Interleukin- 6 is the key cytokine that induces cytokine storm. ${ }^{6,13}$ Similarly, COVID-19 has a high risk of causing thrombosis, which will worsen the patient's clinical condition. ${ }^{14}$

In general, TPE will be beneficial in cytokine storm case and provide hematologic support in the hemophagocytic related case. Contraindications of TPE if the patient condition unstable of hemodynamics and hypoalbumin. TPE with continuous hemofiltration (CHF) was proven to reduce the concentration of IL- 6 and other cytokines in critical pathologies cases such as fulminant liver damage, autoimmune inflammation, neurological and infectious disease. ${ }^{10}$ TPE improves microcirculatory inflammation, clot formation, and hypotension; thus, improving clinical condition comprehensively. ${ }^{3}$ The decrease of pro-inflammation cytokines is followed by clinical improvement marked by the increase in $\mathrm{SaO}_{2}$ after administering TPE twice compared to pre-TPE condition. Clinical improvement is also followed by the radiological improvement observed in the decreasing ground glass opacity in chest X-ray results after the second TPE administration.

This TPE was successful because the patient did not experience severe respiratory failure (PF ratio is $>200$ ); thus, the early case handling is also a factor in the successful TPE administration. ${ }^{2}$ When TPE was administered, the government or organization's standard therapy was also provided concomitantly. ${ }^{10}$ The result of this case report showed that TPE could be administered for COVID-19 case with ARDS and respiratory failure, as reported by other researchers. ${ }^{3}$ Thus, it provides an option in managing severe COVID-19 case. $^{15}$

\section{CONCLUSION}

Therapeutic Plasma Exchange can extract dangerous cytokines, such as IL-6, TNF- $\alpha$ so that the infected body can reach clinical and radiological improvement. Research with a clinical trial is needed to provide further evidence for TPE selection as an option for COVID-19 supportive therapy.

\section{CONFLICT OF INTEREST}

The author(s) declared no potential conflicts of interest with respect to the research, authorship, and/or publication of this case report.

\section{ACKNOWLEDGEMENT}

The author appreciates to UNS hospital and Indonesian Red Cross Surakarta branch who gave cooperation and supports to this -case report.

\section{REFERENCES}

1. Zhang J, Xie B, Hashimoto K. Current status of potential therapeutic candidates for the COVID-19 crisis. Brain, Behavior, and Immunity. 2020;87:59-73.

2. Khamis F, Al-Zakwani I, Al Hashmi S, Al Dowaiki S, Al Bahrani M, Pandak N, et al. Therapeutic plasma exchange in adults with severe COVID-19 infection. International Journal of Infectious Diseases. International Society for Infectious Diseases. 2020;99:214-8.

3. Morath C, Weigand MA, Zeier M, Speer C, Tiwari-Heckler S, Merle U. Plasma exchange in critically ill COVID-19 patients. Critical Care. Critical Care; 2020;24(1):1-4.

4. Keith P, Day M, Perkins L, Moyer L, Hewitt K, Wells A. A novel treatment approach to the novel coronavirus: An argument for the use of therapeutic plasma exchange for fulminant COVID-19. Critical Care. 2020;24(1):13.

5. Gao YM, Xu G, Wang B, Liu BC. Cytokine storm syndrome in coronavirus disease 2019: A narrative review. Journal of Internal Medicine. 2020;(June):1-15. 
6. Tabibi S, Tabibi T, Conic RRZ, Banisaeed N, Streiff MB. Therapeutic Plasma Exchange: A potential Management Strategy for Critically Ill COVID-19 patients. Journal of Intensive Care Medicine. 2020;35(9):827-35.

7. Keith P, Day M, Choe C, Perkins L, Moyer L, Hays E, et al. The successful use of therapeutic plasma exchange for severe COVID-19 acute respiratory distress syndrome with multiple organ failure. SAGE Open Medical Case Reports. 2020;8:2050313X2093347.

8. Song CY, Xu J, He JQ Lu YQ. COVID-19 early warning score: A multi-parameter screening tool to identify highly suspected patients. medRxiv. 2020.

9. Erlina B, Susanto AD, Nasution SA, Ginanjar E, Pitoyo CW, Susilo A, et al. Pedoman tatalaksana COVID-19. 2nd ed. Jakarta, 2020 p. 47-68.

10. Zhuplatov SB, Zhuplatov IS. Removal of endotoxins and cytokines by plasmapheresis filtration with plasma exchange therapy (TPE) could benefit patients with Covid-19 in critical condition. 2020;10(5):85-9.

11. Sokolov AA, Solovyev AG. Russian pioneers of therapeutic hemapheresis and extracorporeal hemocorrection: 100-year anniversary of the world's first successful plasmapheresis. Therapeutic Apheresis and Dialysis. 2014;18(2):117-21.

12. Santis GC De, Correa L, Oliveira O De, Maltoni G, Pina B De, Prado A, et al. Guidelines on the use of therapeutic apheresis in clinical practice - evidence-based approach from the writing committee of the American Society for Apheresis: The seventh special issue. Journal Of Clinical Apheresis. 2011;185(May):181-5.

13. Wang J, Jiang M, Chen X, Montaner LJ. Cytokine storm and leukocyte changes in mild versus severe SARS-CoV-2 infection: Review of 3939 COVID-19 patients in China and emerging pathogenesis and therapy concepts. Journal of Leukocyte Biology. 2020;108(1):17-41.

14. Gucyetmez B, Atalan HK, Sertdemir I, Cakir U, Telci L, Ogan A, et al. Therapeutic plasma exchange in patients with COVID-19 pneumonia in intensive care unit: A retrospective study. Critical Care. Critical Care; 2020;24(1):4-7.

15. Ma J, Xia P, Zhou Y, Liu Z, Zhou X, Wang J, et al. Potential effect of blood purification therapy in reducing cytokine storm as a late complication of critically ill COVID-19. Clinical Immunology. 2020;214:24-6. 